\title{
Breast Cancer Update 2014 - Focus on the Patient and the Tumour
}

\author{
Mammakarzinom Update 2014 - \\ Die Patientin und der Tumor im Mittelpunkt
}

Authors

Affiliations
N. Maass ${ }^{1}$, F. Schütz ${ }^{2}$, P. A. Fasching ${ }^{3}$, T. Fehm ${ }^{4}$, W. Janni ${ }^{5}$, S. Kümmel ${ }^{6}$, H.-C. Kolberg ${ }^{7}$, D. Lüftner $^{8}$, M. Wallwiener ${ }^{2}$, M. P. Lux $^{3}$

The affiliations are listed at the end of the article.

\section{Key words \\ - breast cancer \\ - chemotherapy \\ ๑ hormonal therapy \\ Schlüsselwörter \\ - Mammakarzinom \\ - Chemotherapie \\ - Hormontherapie}

Deutschsprachige Zusatzinformationen online abrufbar unter: www.thieme-connect.de/ ejournals/toc/gebfra

\section{received 11.1.2015 \\ revised 27.1.2015 \\ accepted 27.1.2015}

Bibliography

DOI http://dx.doi.org/

10.1055/s-0035-1545704

Geburtsh Frauenheilk 2015; 75 :

170-182 ๑ Georg Thieme

Verlag KG Stuttgart · New York . ISSN 0016-5751

\section{Correspondence}

Prof. Peter A. Fasching, MD

University Hospital Erlangen

Department of Gynecology

and Obstetrics

Universitätsstraße 21-23

91054 Erlangen

peter.fasching@uk-erlangen.de

\section{Abstract}

The therapy for patients with breast cancer has developed markedly in the past ten years. Our understanding of the molecular biology of tumours and the characteristics of the patients has shaped the recent advances. In this review we present the latest knowledge about the therapy for breast cancer. There are new tests and options not only in the field of anti-HER2 therapy but also in the management of triple negative and hormone receptor-positive patients. Comprehension of prognosis and therapeutic response to chemotherapies is little by little helping to define patient groups who will not respond to chemotherapy or who do not need treatment because their prognosis is extremely good. In the field of anti-HER2 therapy, work is continuing on the development of drugs suitable for and able to overcome trastuzumab resistance. For hormone receptor-positive cancers, we now have a better understanding of which therapy groups will benefit from which anti-endocrine drugs, and which will be able to overcome a possible resistance (treatment of the PI3K pathways, inhibition of the cell cycle). Molecular tests are still being evaluated with regard to the clinical situations in which they may have the greatest relevance for therapeutic decisionmaking; however, evidence is also increasing as to the fields in which good predictions for the prognosis can be obtained. On the whole, more work is needed to promote our understanding of the new developments in diagnostics and therapy and to involve both physicians and patients equally in the procedures.

\section{Zusammenfassung \\ $\nabla$}

Die Therapie von Patientinnen mit Mammakarzinom hat sich in den letzten 10 Jahren deutlich weiterentwickelt. Das Verständnis um die molekulare Biologie der Tumoren und Patientinneneigenschaften haben die jüngsten Entwicklungen geprägt. In diesem Review werden die neuesten Erkenntnisse zur Therapie des Mammakarzinoms dargestellt. Hierbei gibt es sowohl auf dem Gebiet der Anti-HER2-Therapie als auch bei der Behandlung von triple-negativen und hormonrezeptorpositiven Patientinnen neue Tests und Therapien. Das Verständnis um Prognose und Therapieansprechen auf Chemotherapien definiert nach und nach Patientinnengruppen, die nicht auf eine Chemotherapie ansprechen oder die keine Therapie benötigen, weil die Prognose außerordentlich gut ist. Auf dem Gebiet der Anti-HER2-Therapie wird weiterhin an Medikamenten gearbeitet, die bei einer Trastuzumab-Resistenz geeignet sind, diese zu überwinden. Für hormonrezeptorpositive Karzinome wird besser verstanden, welche Therapiegruppen von welchen antiendokrinen Medikamenten profitieren, und welche eine eventuelle Resistenz überwinden können (Behandlung des PI3K-Pathways, Inhibition des Zellzyklus). Molekulare Tests befinden sich weiterhin in der Evaluation, in welchen klinischen Situationen sie den größten Nutzen für Therapieentscheidungen bringen können, jedoch wächst die Evidenz, in welchen Bereichen eine gute Aussage über die Prognose gewonnen werden kann. Insgesamt muss daran gearbeitet werden, das Verständnis für die neuen Entwicklungen in Diagnostik und Therapie zu fördern und Ärzte und Patientinnen gleichermaßen in die Ausbildung mit einzubeziehen. 


\section{Introduction}

\section{$\nabla$}

In the past few years the detection and treatment of breast cancer have focussed more and more on the characteristics of the individual patient and her tumour $[1,2]$. The basis for this is the extensive knowledge about the molecular biology of the patient and the tumour. Even with the continuing high incidence, this has led to a reduction in mortality [3]. In the present review we survey the current developments on the basis of new knowledge presented at the last congresses (ASCO 2014, ESMO 2014 and San Antonio Breast Cancer Symposium 2014) and the latest reports in the literature.

\section{Neoadjuvant Therapies \\ $\nabla$}

Neoadjuvant or primary systemic therapy (PST) is in the meantime a standard for the treatment of breast cancer. Its original main role of reducing the size of the tumour to enable a better surgical procedure has changed drastically. Tumour biological criteria and criteria adapted to the therapeutic response are becoming more and more important in the choice of treatment [4, 5]. The recognition of a pathologically complete remission (pCR) as marker for survival must also be considered in a more differentiated manner $[6,7]$. Thus, in cases of increasingly aggressive tumour biology, an effect in favour of improved survival depending on the pCR is becoming apparent [8]. But, even in the group of triple negative breast cancers (TNBC), this is possibly dependent on the BRCA mutation status [9]. A further point is that local therapeutic algorithms, e.g., mastectomy rates, sentinel lymphadenectomy (SNB) and radiotherapy, have not yet been sufficiently adapted to the above-mentioned treatment criteria [10].

One constantly recurring question in the treatment of TNBC is about the relevance of platinum-containing chemotherapy. First analyses and preclinical data have demonstrated a markedly higher efficacy for DNA damaging cytostatic agents [11]. In the course of the GeparSixto study [12], 315 triple negative breast cancer patients, among others, were treated with or without carboplatin. A significantly higher pCR rate was found for the additional administration of carboplatin (53.2\%, 95\% confidence interval [CI]: $54.4-60.9$ vs. 36.9\%; 95\% CI: 29.4-44.5; p =0.005). In contrast, in the subgroup with HER2-positive tumour biology this effect was not apparent [12]. On further analysis, in the subgroup with a positive family history of breast or ovarian cancer, the pCR rate was seen to be increased by $26 \%$ [13], by $23 \%$ in the subgroup with BRCA1/BRCA2/RAD51 germ-line mutation and by merely $11 \%$ in the absence of the above-mentioned additional criteria [13]. In an Isreali study with a few triple negative breast cancer patients $(n=80)$, however, it was found that pCR was not a surrogate marker for survival in patients with a BRCA mutation [9]. Thus, it remains to be seen whether or not the significant improvement in $\mathrm{pCR}$ achieved by the additional administration of carboplatin to patients with triple negative breast cancer and a coexisting mutation or positive family history can also be reflected in overall survival [13].

In the neoadjuvant situation anthracycline- and taxane-containing therapies are now standard treatments. The most frequently employed therapeutic scheme for taxane-containing treatment involves the weekly administration of paclitaxel. In the course of the GeparSepto study, weekly nab-paclitaxel was also compared in an experimental arm [14]. The rationale for this was based on data from metastatic situations in which a prolonged progres- sion-free period was observed with nab-paclitaxel in comparison with docetaxel [15]. In addition, in the study design taxanes were administered upfront, prior to the usual EC therapy in order, if possible, to achieve an even higher $\mathrm{PCR}$ rate, as shown by the data of the Neo-Tango study [16]. Altogether 1204 patients were included in the intention-to-treat analysis. As a result of an interim analysis after treatment of 400 patients, the administered dose of nab-paclitaxel was reduced from $150 \mathrm{mg} / \mathrm{m}^{2}$ to $125 \mathrm{mg} / \mathrm{m}^{2}$. After this dose de-escalation, among others, the rates of peripheral neuropathies in both study arms were comparable. With regard to the primary endpoint (pCR; ypT0; ypN0), there was a significant difference in favour of nab-paclitaxel (nab-paclitaxel 38\% vs. paclitaxel 29\%; p-value: 0.001 ). In the subgroup analysis this effect was most strongly pronounced for patients with triple negative breast cancer (OR: 2.69). It remains to be seen in the followup whether the increased pCR rate is also reflected in the overall survival.

As yet nab-paclitaxel is only authorised for the metastatic situation, but already has found use in many adjuvant and neoadjuvant study concepts (e.g., ADAPT umbrella programme).

\section{Surgical Therapies \\ $\nabla$}

Sentinel lymph node removal for patients under neoadjuvant chemotherapy

The development of surgical therapy in the past few years has been essentially influenced by an increase in the options for reconstructive surgery in the course of ablative breast operations as well as, above all, by the reduction in invasiveness of axilla staging, which in the past few years was again repositioned by the Committee Mamma of the Consortium for Gynaecological Oncology (Kommission Mamma der Arbeitsgruppe für gynäkologische Onkologie [AGO-Mamma]) also in the context of PST [17]. Patients exhibiting axillary lymph node attack prior to the start of neoadjuvant chemotherapy represent a special collective (cN1). In clinical routine, pretherapeutic clarification by means of high-speed core-needle biopsy for histological analysis or fine needle aspiration biopsy for cytological determination of lymph node status have become established. Especially against the background of the data from the ACOSOG-Z0011 study [18], the question arises whether or not patients exhibiting complete remission in the axilla will gain any benefit at all from an axillary lymphadenectomy which in itself is associated with a certain amount of morbidity for the patients.

Two large studies have addressed this question, namely the German SENTINA study and ACOSOG Z1071 [19,20]. In SENTINA study, 4 cohorts were examined in order to assess the value of SNB before and after neoadjuvant chemotherapy. 1022 patients underwent SNB prior to PST. In this group a remarkable detection rate of $99.1 \%$ was observed. In those patients with positive sentinel lymph nodes or cN1 before PST, it was tested whether a renewed SNB after PST is an adequate method for staging the axilla. However, it was found in this group that the detection rate was merely $60.8 \%$ and the false negative rate (FNR) amounted to $51.6 \%$ [19]. Both values must be considered as insufficient for a staging. However, a subgroup of patients who initially had a positive sentinel node and who achieved a complete clinical remission in the axilla region in the course of PST exhibited a significantly better detection rate (80.1\%) and lower FNR (14.2\%) [19]. But this FNR is also higher than that for SNB prior to PST. It was observed in the study that the FNR correlated with the number of 
Table 1 Recommendations of AGO-Mamma for surgical therapy of the axilla before and after neoadjuvant chemotherapy; from [17].

\begin{tabular}{|c|c|c|c|c|c|c|}
\hline & & & & $\begin{array}{l}\text { Oxford } \\
\text { LoE }\end{array}$ & $\begin{array}{l}\text { Oxford } \\
\text { GR }\end{array}$ & $\begin{array}{l}\text { AGO } \\
\text { GR }\end{array}$ \\
\hline \multicolumn{7}{|c|}{ SLNB before or after NACT for CNO } \\
\hline SLNB before NACT & & & & $2 b$ & B & + \\
\hline SLNB after NACT & & & & 3 & B & \pm \\
\hline \multicolumn{7}{|c|}{ Further surgical therapy in dependence on SLNB } \\
\hline cN status (before therapy) & pN status (after therapy) & cN status (after therapy) & surgical procedure & & & \\
\hline cNO & pNO(sn) & - & nihil & 1a & A & + \\
\hline cN0 & $\mathrm{pN}+(\mathrm{sn})$ analogous to $\mathrm{ACOSOG} \mathrm{Z} 11^{*}$ & ycNO & ALND & 3 & B & \pm \\
\hline cNO & $\mathrm{pN}+(\mathrm{sn})$ not analogous to $\mathrm{ACOSOG}^{*}$ & ycNO & ALND & $2 b$ & B & + \\
\hline \multirow[t]{3}{*}{$\mathrm{cN}+$} & $\mathrm{cN}+(\mathrm{CNB} / \mathrm{FNA})$ & ycNO & SNB & 3 & B & \pm \\
\hline & & & ALND & $2 b$ & B & + \\
\hline & & $\mathrm{ycN}+(\mathrm{CNB} / \mathrm{FNA})$ & ALND & $2 \mathrm{~b}$ & B & ++ \\
\hline
\end{tabular}

* T1/T2, BET, 1-2 SLN pos., tangential field irradiation of the breast

NACT: neoadjuvant chemotherapy; LoE: level of evidence; GR: grade of recommendation; SLNB: sentinel lymph node biopsy; ALND: axillary lymphadenectomy; CNB: core-needle biopsy; FNA: fine needle aspiration; ACOZOG: American College of Surgeons Oncology Group

removed sentinel lymph nodes. Thus, the FNR was $24.3 \%$ in the case of one detected sentinel lymph node, $18.5 \%$ in the case of 2 detected sentinel lymph nodes and an FNR of below $10 \%$ was first achieved in cases with 3 removed sentinel lymph nodes, this can be considered as cut-off for the sensitivity of SNB.

On the whole, the ACOSOG Z1071 study provided very similar results [20]. Here no sentinel lymph nodes after PST could be detected in $7.1 \%$ of the patients. In $12 \%$ of the cases only one sentinel lymph node was removed, in over $80 \%$ of the cases, respectively, 2 or more nodes were removed. The number of excised lymph nodes in this study appeared to be due in $79.1 \%$ of the cases to double marking (colour marking and radioactive marking) of the sentinels [20]. The FNR in this study amounted to $12.6 \%$ (in the case of 2 or more removed sentinel lymph nodes). A widely congruent observation, however, was seen in the relation between the number of excised sentinel lymph nodes and the FNR. Thus in the case of one excised sentinel lymph node the FNR was $31.5 \%$, for two sentinel lymph nodes $21.1 \%$ and only at 3 or more removed sentinel lymph nodes did the FNR amount to less than $10 \%$ [20]. Both studies independently from each other demonstrated that the FNR after neoadjuvant chemotherapy is less favourable than that for primary sentinel lymph node biopsy before PST $[19,20]$.

The recommendations of AGO-Mamma paint a corresponding picture to the study data [17]. Thus, AGO-Mamma [17] recommends for cNO a sentinel lymph node biopsy before chemotherapy (AGO recommendation level "+"). In cases with clinically positive axilla ( $\mathrm{cN} 1$ ) before PST and those still with clinically attacked lymph nodes after chemotherapy, axilla resection is recommended (AGO recommendation level "+"). For those patients who achieve a complete clinical remission of the axilla, SNB after PST has merely the recommendation level " \pm " whereas axillary lymphadenectomy is recommended at the level "+". In the case of cNO patients before neoadjuvant chemotherapy, SNB should be performed before PST since this is associated with a lower FNR [17].

The recommendations of AGO-Mamma are summarised in - Table 1.

Further development of the indication for mastectomy Breast cancer patients often receive too much therapy and undergo mastectomy and/or chemotherapy. In a recent study it was shown that the local risk for developing metastatic disease can be measured with a multi-gene test (PAM-50) [21-24]. In the PAM-50 gene test 58 genes are examined and analysed. The result is expressed as a risk-of-recurrence (ROR) score. The ROR score includes the various disease parameters in order to subsequently assess the individual risk. In the study 1308 patients of the ABCSG-8 study were included. Altogether, $59 \%$ of the patients were less than 65 years old, $79 \%$ of them had undergone a breastpreserving therapy (BET) and $32 \%$ had positive lymph nodes. On the basis of the results of the PAM-50 gene test, $72 \%$ had a low ROR score, $68 \%$ were Luminal type A, $28 \%$ were Luminal type B. After a follow-up period of 11 years, 34 local recurrences were reported. This study revealed that the PAM-50 ROR score represents a predictive marker for a local recurrence, independent of age, tumour size or lymph node status $(p<0.0002)$. For cases of low/intermediate risk a local recurrence risk of merely $1.6 \%$ is described. The multivariate analysis shows that BET is also an option for high-risk patients. In addition, the surgical therapy should be oriented on the tumour biology.

Similar attempts to predict the probability of a local recurrence were undertaken with the EndoPredict score [25-27], another multigene test [28]. It can be expected that, when such study results are confirmed, molecular tests will also be incorporated into the decision-making process for local therapies.

\section{Adjuvant Therapy}

$\nabla$

\section{Adjuvant antihormonal therapy in premenopausal} women

The systemic therapy for breast cancer has developed in the past years in the direction that some patients benefit from chemotherapy whereby the indication has again been restricted in the light of our increasing knowledge on prognostic groups and therapy responses. However, it is undisputed that all hormone receptor-positive patients should receive an anti-endocrine therapy. Therapy of choice in such cases is tamoxifen for premenopausal patients as well as aromatase inhibitors and tamoxifen for postmenopausal patients.

New data on adjuvant endocrine therapy for breast cancer have generated particular interest. Therapy with tamoxifen for at least 5 years is considered as the standard for patients with endocrinesensitive tumours. Depending on the risk profile of the initial disease, therapy with tamoxifen can be extended by five years or - 
on transition into the postmenopause - by addition of an aromatase inhibitor [29]. To what extent an aromatase inhibitor can be administered in the premonopause was one objective of the TEXT and SOFT studies [30-32].

In the SOFT study (Suppression of Ovarian Function Trial) premenopausal patients were prospectively randomised into three study arms. They received either tamoxifen (Tam), tamoxifen combined with GnRH analogues for suppression of ovarian function (OFS) or exemestane in combination with OFS (E+OFS), for five years each. Primary study target was the comparison of Tam vs. Tam + OFS. In accord with an amendment, the comparison of exemestane + OFS with Tam alone was a secondary study target. $53 \%$ of the study participants had undergone a previous chemotherapy while the remainder had received an exclusive endocrine therapy. As expected the chemotherapy patients had a more aggressive tumour biology (G3 7 vs. 35\%) and locally advanced tumours, e.g., $57 \%$ had positive lymph nodes, this was the case in only $9 \%$ in the group without previous chemotherapy [30]. In the analysis for disease-free survival as primary study objective, no significant differences between Tam and Tam + OFS (84.7\% 5-year disease-free survival vs. $86.6 \%$ ) were seen after a median of 5.6 years [33]. The addition of exemestane (E + OFS) showed a significantly better disease-free survival (89\%, HR in comparison to tamoxifen: $0.68 ; 95 \% \mathrm{CI}: 0.53-0.86$ ) [33]. This is also reflected in the analysis of the subgroup of patients who did not receive an initial chemotherapy. In these cases the rates of breast cancer-free survival were $95.8 \%$ in the tamoxifen arm, 95.1\% in the Tam + OFS arm and 97.1\% in the E + OFS arm [33]. These differences are not significant. In the subgroup of very young patients with an initial chemotherapy (younger than 35 years, $n=350$ ), however, a stepwise improvement in breast cancer-free survival from $67.7 \%$ (Tam) through $78.9 \%$ (Tam + OFS) to $83.4 \%$ (E + OFS) was observed. Both arms with OFS exhibited significantly better survival rates than did those patients who were treated with tamoxifen alone. However, no data on the impact on overall survival were presented [33].

The data can be interpreted so that for endocrine therapy in the premenopause a further option is available for very young patients, namely the combined use of exemestane and GnRH analogues. The benefit in breast cancer-free survival achieved by the addition of GnRH analogues is accompanied by a high rate of side effects such as hot flushes, sweating and, e.g., dry vaginal mucous membranes which seem to decline somewhat over time.

\section{Adjuvant chemotherapy}

New data on adjuvant chemotherapy were presented in the ICE study (Ibandronate with or without Capecitabine in Elderly Patients) [34]. Here the clinically very interesting option was investigated as to whether the use of capecitabine $\left(2000 \mathrm{mg} / \mathrm{m}^{2}\right)$ can positively influence the disease course, especially in older patients ( $>65$ years) with node-positive or medium-risk breast cancer who were all receiving the bisphosphonate ibandronate (50 mg daily, oral, or alternatively $6 \mathrm{mg}$ i.v. every four weeks). For the on average 71-year-old patients there were no significant differences between the study arms with regard to disease-free survival and overall survival. A positive result worthy of note is that the survival rate of this population after 5 years amounted to more than $87 \%$ [34].

For patients older than 65 years with not low-risk breast cancers, excellent 5-year survival rates can be achieved by the addition of ibandronate orally or intravenously to the possibly indicated adjuvant endocrine therapy. The additional administration of cape- citabine does not improve the situation. The question remains open of whether the addition of another combination partner instead of capecitabine, e.g., $4 \times \mathrm{AC}$ or $6 \times \mathrm{CMF}$ would have caused an improvement.

Two questions about adjuvant chemotherapy were definitively answered in the studies. On the one hand the equivalence of $4 \times$ AC with $6 \times \mathrm{FEC}_{100}$ was demonstrated in the B-36 study [35]. After more than 8 years, disease-free survival rates of over $82 \%$ were seen in both arms [35]. Furthermore, after 12 years followup in the study E1199 on 4950 patients the equivalence of the administration frequencies of weekly vs. 3-weekly for the two tubule inhibitors pacli- and docetaxel was demonstrated [36]. As the results, it was found that - as used in clinical practice - the weekly administration of paclitaxel and the 3-weekly administration scheme for docetaxel were more beneficial than the comparator. In explorative subgroup analyses it was seen in cases of triple negative breast cancer that the use of weekly paclitaxel resulted not only in better disease-free but also overall survivals. In contrast and interestingly, for hormone receptor-positive breast cancers there was a trend in favour of the 3-weekly administration of docetaxel with regard to overall survival.

Due to the demonstration of the equivalence of $4 \times$ AC with $6 \times$ FEC, the patients can be spared from 2 cycles of chemotherapy, although modern chemotherapy regimens do contain a taxane. With regard to the taxanes, not only the weekly administration of paclitaxel - rather for triple negative cancers - but also the 3-weekly administration of docetaxel - rather for hormone receptor positive cancers - can be performed. As known from clinical practice, the weekly administration of paclitaxel is better tolerated by the patients with regard to side effects.

\section{Treatment of Metastatic Breast Cancer}

\section{$\nabla$}

\section{Chemotherapies for metastatic patients}

In the era of targeted therapies for and molecular classifications of breast cancer, studies on pure chemotherapies and really new accomplishments in the metastatic situation have become rare. Besides anthracyclines and taxanes, monochemotherapies with capecitabine or eribulin are standards [17]. In special cases in which a rapid remission needs to be achieved, combination chemotherapies are required. The data situation for the later lines of treatment in such cases is weak. A phase II study on the combination of capecitabine and eribulin has just been presented [37]. Patients with up to three previous therapies including anthracycline and taxane $(n=42)$ received capecitabine $\left(2000 \mathrm{mg} / \mathrm{m}^{2}\right.$ body surface), d1-14, and eribulin ( $1.4 \mathrm{mg} / \mathrm{m}^{2}$ body surface), d1, $\mathrm{d} 8, \mathrm{q} 21 \mathrm{~d}$. On average the patients were treated with 8 cycles. An objective response rate (ORR) of $42.9 \%$, a clinical benefit of $57.1 \%$ and a progression-free survival of 7.2 months (95\% CI 4.5-10.8) were recorded. With regard to toxicities of all degrees, neutropenia $(81.0 \%)$, nausea (28.6\%), diarrhoea (19.0\%) and alopecia (35.7\%) were the main ones. 3rd and 4th degree toxicities concerned above all only neutropenia (69.0\%). Thus, data for the combination with an ORR of $42.9 \%$ are now available. Comparable phase II studies with the two substances as monotherapies gave an ORR of $11.5 \%$ for eribulin or $26.0 \%$ for capecitabine [38, 39].

In the use of chemotherapies, not only the quality of life but also management of the toxicity play significant roles. The use of erythropoietin in therapy for breast cancer patients has markedly declined due to hints for an increased mortality [40-43]. The re- 
sults of a randomised phase III study on the use of epoetin-alfa in the metastatic situation have recently been presented [44]. Patients in the first-line situation with an $\mathrm{Hb}$ value of $\leq 11 \mathrm{~g} / \mathrm{dL}$ received either a standard chemotherapy $(n=1050)$ or the therapy plus epoetin-alfa (40000 IU per week; $n=1050$ ). With 7.4 months, the progression-free survivals in both arms were identical (HR 1.069; 95\% CI 0.988-1.200) [44]. Also no significant difference in overall survival could be seen (17.2 months and 17.4 months; HR 1,057). $5.8 \%$ of the patients in the study arm required a transfusion while in the control arm this was the case for $11.4 \%$. The thrombosis rate in the therapy arm was, however, twice as high (2.8 vs. 1.4\%) [44]. Although the study could not identify any influence of the use of epoetin on mortality, the authors emphasise that the course of the curves for PFS and OS were slightly divergent so that a problem could possibly arise. Thus, they consider the use of epoetin to be possible but recommend that the indication be restricted to anaemic patients in a palliative situation.

The therapy for patients with a triple negative breast cancer, especially those in a metastatic condition, is a particular challenge. Patients with triple negative breast cancer have early cerebral metastases and a rapid progression under chemotherapy. In such a situation platinum salts are being increasingly used as chemotherapy. The underlying idea is that ca. $10-15 \%$ of all TNBC are associated with a mutation in the BRCA1/2 gene $[45,46]$ and further TNBC could possess a "BRCAness", i.e., can react like a hereditary breast cancer. In the course of an English study the use of carboplatin was evaluated in comparison to that of docetaxel [47]. 376 patients with a TNBC in the metastatic advanced recurrence situation received either 6 cycles of carboplatin (AUC6), q21 d, or six cycles of docetaxel ( $100 \mathrm{mg} / \mathrm{m}^{2}$ body surface), q21 d. The primary endpoint was the ORR after cycle 3 and 6 . The median follow-up amounted to 11.0 months. Altogether, more side effects occurred under docetaxel such as, e.g., fatigue syndrome, neuropathy and, above all, febrile neutropenias $(\mathrm{p}<0.01)$ as well as infections. After a change in the protocol and the addition of $\mathrm{G}$-CSF in the docetaxel arm, the incidence of febrile neutropenias could be reduced. With regard to the primary endpoint, the entire collective did not show any significant differences in objective responses (31.4\% under carboplatin, 35.6\% under docetaxel, $\mathrm{p}=0.44$ ). Even in heavily pre-treated patients a response could still be seen. The median PFS of 3.1 months or, respectively, 4.5 months were not significantly different $(p=0.29)$. The median overall survivals amounted to 12.4 or, respectively, 12.3 months. Of particular interest was the analysis according to mutation status. Carriers of the BRCA1/2 mutation showed a markedly better response of $68 \%$ under carboplatin than under docetaxel with $33.3 \%(p=0.03)$ [47]. Also the PFS was significantly lengthened by 2 months ( 6.8 vs. 4.8 months, $\mathrm{p}=0.03$ ) in carriers of the mutation under carboplatin. The homologous repair deficiency (HRD) testing of the tumour in order to detect a BRCAness in these cases surprisingly had no influence on the results.

The results emphasise the necessity in future to more often perform genetic testing of patients already suffering from triple negative breast cancer and/or having familiar predispositions [45] in order to be able to initiate targeted therapies - this holds not only for carboplatin, but also for PARP inhibitors that are currently being tested in studies. Currently recruiting studies in Germany on the metastatic situation in triple negative breast cancer are the EMBRACA [48] (NCT01945775) and the ABRAZO [49] (NCT02034916) studies [50].

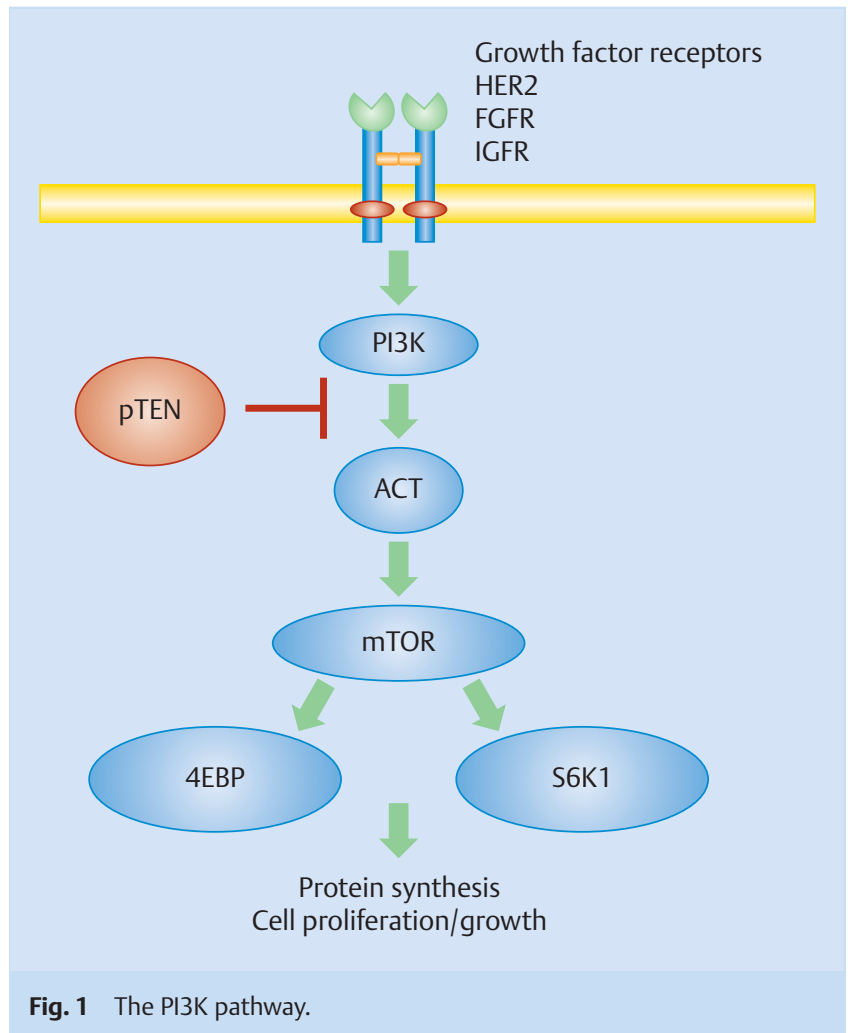

\section{$\mathrm{PI} / 3 \mathrm{~K} / \mathrm{mTOR}$ inhibition in metastatic patients}

The PI3K/AKT/mTOR pathway plays a central role for the survival of the cell, for cell growth, cell proliferation and motility as well as cell metabolism [51]. The signal transduction path can be activated in various ways. Growth factors bind to the receptor tyrosine kinases (e.g., HER2, IGFR). In this way PI3K is phosphorylated and thus the PI3K/AKT/mTOR signal path is activated. An inhibitor of PI3K is the tumour suppressor gene PTEN which can hinder the activation of AKT. A simplified summary of the cascade is shown in - Fig. 1. The PI3K/AKT/mTOR pathway is hyperactivated in many tumours and thus also in breast cancer. The causes of this are on the one hand somatic mutations in the genes PTEN, PIK3CA or AKT. On the other hand, the signal transduction route can be overactivated by amplifications/mutations of receptor tyrosine kinases (e.g., HER2). In the case of hormone receptor positive breast cancer there is in addition an intensive crosstalk between ER and PI3K signal transduction. This crosstalk is considered to be responsible for the development of endocrine resistance [52].

On the strength of the central role of the PI3K/AKT/mTOR pathway, numerous targeted therapies that inhibit one or more interfaces of this pathway have been developed in the past few years. The developments that have undergone the most progress involve the mTOR and PI3K inhibitors. As pure monotherapies, these substances have shown only marginal therapeutic activities [51]. Since the PI3K/AKT/mTOR pathway plays an important role for endocrine resistance, mostly aromatase inhibitors or fulvestrant are combined with an inhibitor of the pathway in study concepts ( Table 2). In the meantime the use of the MTOR inhibitor everolimus with exemestane is the standard in clinical routine as first- and second-line therapy for metastatic breast cancer in cases of (clinically suspected) endocrine resistance. On the other hand PI3K inhibitors are still the subject of phase I-III studies 
Table 2 Current clinical study landscape on mTOR and PI3K inhibition.

\begin{tabular}{|c|c|c|c|c|c|}
\hline Substance & Inhibition & Phase & $\mathbf{n}$ & Combination partners & Clinical benefit \\
\hline Everolimus (BOLERO-2) & mTOR & III & 724 & exemestane & PFS: 10.6 months vs. 4.1 months [113] \\
\hline Tamoxifen (TAMRAD) & mTOR & II & 111 & tamoxifen & TTP: 8.6 months vs. 4.5 months [114] \\
\hline Everolimus (BOLERO-1) & $\begin{array}{l}\text { MTOR } \\
\text { HER2 }\end{array}$ & III & 719 & paclitaxel/trastuzumab & $\begin{array}{l}\text { PFS: } 14.95 \text { months vs. } 14.49 \text { months [ } 61] \\
\text { AE related on treatment deaths increased }\end{array}$ \\
\hline Everolimus (BOLERO-3) & $\begin{array}{l}\text { MTOR } \\
\text { HER2 }\end{array}$ & III & 569 & vinorelbine/trastuzumab & $\begin{array}{l}\text { PFS: } 7.00 \text { months vs. } 5,78 \text { months } \\
\text { high SAE rate! } !^{2}[115]\end{array}$ \\
\hline Ridaforolimus & mTOR & II/random. & 80 & dalotuzumab/exemestane & $\begin{array}{l}\text { PFS: not significant }{ }^{3} \\
\text { HR 1.18; } 80 \% \text { Cl: } 0.8-1.72 ;(p=0.565) \text { [116] }\end{array}$ \\
\hline BKM120 (burparlisib) & $\begin{array}{l}\text { PI3K } \\
\text { class I (pan) }\end{array}$ & $\mathrm{Ib}$ & 51 & letrozole & Clinical benefit rate: $31 \%$ [117] \\
\hline BKM120 (burparlisib) & $\begin{array}{l}\text { PI3K } \\
\text { class I (pan) }\end{array}$ & 1 & 31 & fulvestrant & evidence for antitumour activity [118] \\
\hline $\begin{array}{l}\text { GDC0941 (pictilisip) } \\
\text { FERGIE trial }\end{array}$ & $\begin{array}{l}\text { PI3K } \\
\text { class I (pan) }\end{array}$ & II/random. & 168 & fulvestrant & $\begin{array}{l}\text { PFS: } 6.6 \text { months vs. } 5,1 \text { months }{ }^{4} \text { [119] } \\
\text { more benefit for ER/PR-positive tumours }\end{array}$ \\
\hline BYL719 & $\begin{array}{l}\text { PI3K } \\
\text { selective } \\
\text { (class } 1, \alpha \text { ) }\end{array}$ & 1 & 64 & $\begin{array}{l}\text { fulvestrant stratified accord- } \\
\text { ing to PI3K mutations }\end{array}$ & evidence for antitumour activity ${ }^{5}[120]$ \\
\hline BYL719 & $\begin{array}{l}\text { PI3K } \\
\text { selective } \\
\text { (class } 1, \alpha \text { ) }\end{array}$ & 1 & 14 & letrozole or exemestane & evidence for antitumour activity [121] \\
\hline
\end{tabular}

1 Serious adverse event death due to everolimus treatment significantly increased ( 0 vs. 36\%)

2 High SAE rate in everolimus arm (42 vs. $20 \%$ )

323.3 weeks (with Ridaforolimus) vs. 31.9 weeks

${ }_{4}^{4}$ Not statistically significant; PIK3CA mutations were not predictive for a therapy response

${ }^{5}$ Partial remissions were only seen for patients with PIK3CA mutations

( Table 2). For this class of compounds we distinguish between pan-PI3K inhibitors of class I, which block all isoforms of class I PI3K $(\alpha-\delta)$, and the selective PI3K inhibitors, which only specifically inhibit individual isoforms. As a rule the isoform PI3K- $\alpha$ is the target, since this gene most frequently exhibits mutations ( Table 2). The specific blockade of PI3K isoforms requires only low doses for inhibition and this also means less toxicity. Furthermore a high therapeutic effect is to be expected [51].

Other study concepts employ PI3K/AKT/mTOR inhibitors with trastuzumab in order to avoid trastuzumab resistance ( Table 2). Phase III data show that no or only a marginal benefit is achieved for HER2-positive patients by the additional administration of the mTOR inhibitor everolimus and this only at the cost of a significantly increased toxicity. For this reason it must be assumed that the dual blockade of AHER2 and mTOR will not find acceptance into clinical routine. Table 2 summarises the most important current studies on PI3K/mTOR inhibition.

\section{CDK4/6 inhibition in patients with metastatic disease}

Dysregulation of the cell cycle is one of the major characteristics of cancer disease. The family of cycline-dependent kinases (CDK) plays a decisive role in the regulated and controlled course of the cell cycle. CDK 4 and 6 and cycline D regulate the transition from the G1 phase into the S phase by an influence on the phosphorylation state of $\mathrm{pRb}$ (phosphorylated retinoblastoma). In the case of hyperphosphorylation of $\mathrm{pRb}$, transcription factors are liberated that make the G1/S transition possible and so upregulate progression of the cell cycle [53]. For a better understanding the influence of CDK4/6 on proliferation and cell survival is schematically illustrated in $\odot$ Fig. 2.

Three substances for the inhibition of this activity of CDK4/6 are currently undergoing clinical testing in advanced breast cancer disease: palbociclib (PD-0332991), ribociclib (LEE011) and abemaciclib (LY2835219). The development of palbociclib is the most advanced. Already in 2009 the inhibitory effect of palbociclib, especially on ER-positive and HER2-overexpressing breast cancer cells, was demonstrated in the framework of in-vitro investigations with breast cancer cell lines [54]. Clinically the focus was first directed to its further development in the direction of ER-positive, metastatic breast cancer. In the phase II study PALOMA-1/TRIO-18, 165 patients with oestrogen receptor-positive, HER2-negative breast cancer were randomised and treated in the first line for metastatic disease with letrozole plus placebo vs. letrozole plus palbociclib. The PFS for the combination of letrozole with the CDK4/6 inhibitor was 20.2 months vs. 10.2 months for letrozole alone. The difference was highly significant with a $\mathrm{p}$ value of 0.0004 . The most important side effects were the expected haematotoxicity and fatigue [55]. At present the further development of CDK4/6 inhibitors is considered to be one of the most promising options for ER-positive, metastatic breast cancer, whereby a particular emphasis has to be placed on the investigation of predictive factors for a response. A phase III study on palbociclib is currently in the recruitment stage [55, 56]. Since the first presentation of the data at the AACR Meeting in San Diego in the spring of 2014, the FDA is considering an accelerated authorisation of palbociclib.

Also the available data on abemaciclib [57] and ribociclib [58] show clinical efficacy in combination with endocrine therapies and no unexpected warning signs, both substances are also being tested in phase III studies. For ribociclib, data are available from phase Ib for its combination with letrozole and the PI3K-inhibitor BYL719, however, at present only the combination with letrozole is being examined in a phase II trial [58]. The currently active study programmes on CDK4/6 inhibitors for metastatic breast cancers are presented in $\bigcirc$ Table 3.

The good data available to date for CDK4/6 inhibitors in ER-positive HER2-negative, metastatic breast cancer were also reflected in the planning of the phase III study Penelope B of GBG which is 


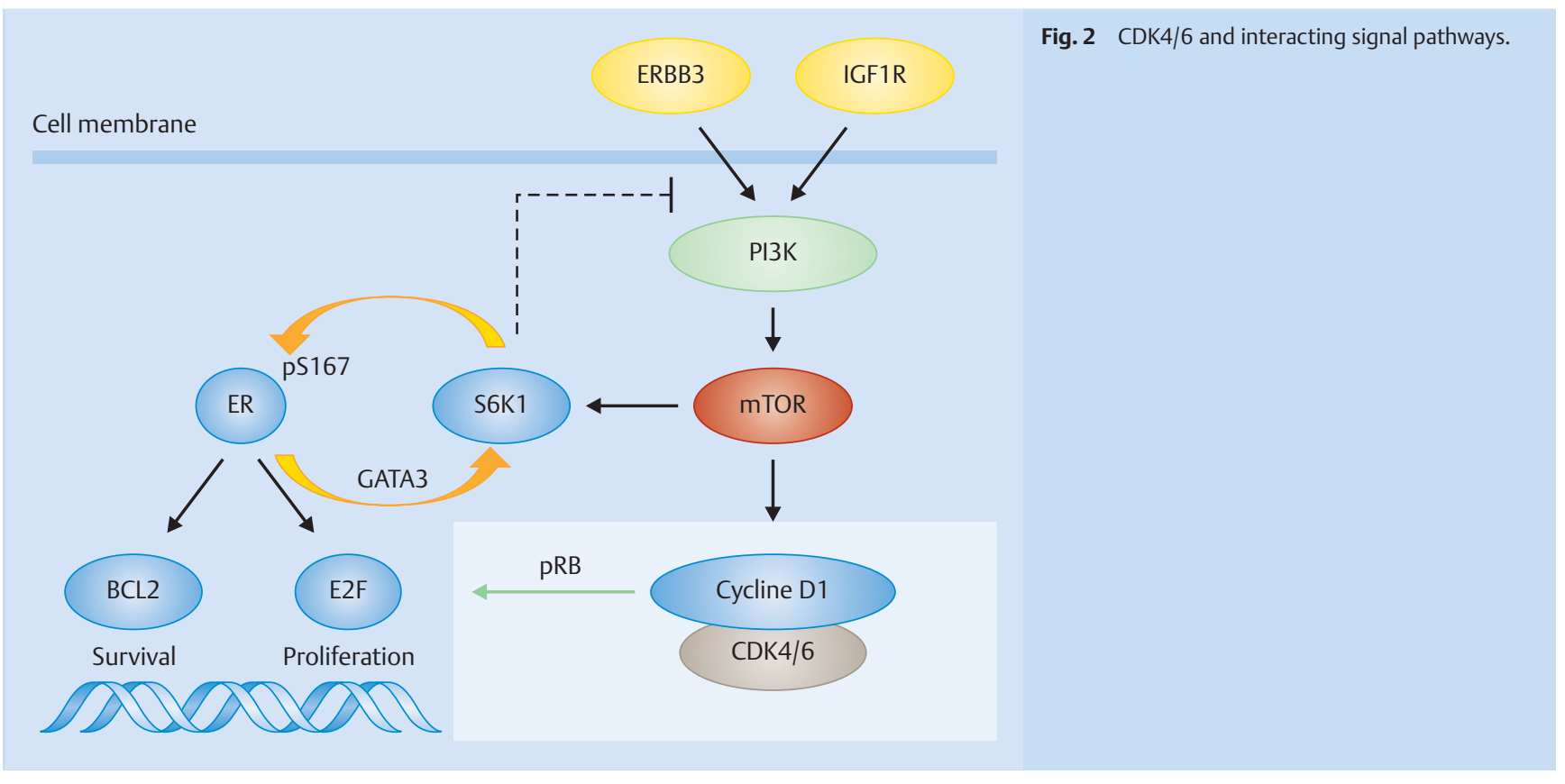

currently in the recruiting phase; this will examine the use of palbociclib in patients with tumour residues after neoadjuvant chemotherapy and with a high risk of recurrence. This study is also intended to answer a question that arises with all new substances and is important for restriction to the metastatic situation or the use in adjuvant, neoadjuvant or post-neoadjuvant therapies, namely the question about the carry-over effect, or does the substance still also exhibit activity after conclusion of the treatment.

In summary, the CDK4/6 inhibitors represent one of the most highly promising innovations in the management of breast cancer disease of the past few years. While their introduction into clinical routine for the metastatic situation can already be expected within the next two years, data on their post-neoadjuvant use will of course not be available until later.
Anti-HER therapy for patients with metastatic disease Not all HER2-positive breast cancers respond to anti-HER2 therapies. Reasons for this primary (but also secondary) resistance can be a down-regulated HER2 expression in the course of the disease, an up-regulated pro-survival signal and, especially in the case of the cytostatics-trastuzumab conjugate T-DM1, an increased efflux function of medicament pumps.

A possibility to overcome the resistance may lie in the development of T-dependent bispecific antibodies (TDB) ( Fig. 3). Here, one "little arm" of the antibody is developed against CD3, a lymphocyte-specific antigen, and the other "little arm" against a tumour-specific antigen so that a direct polyclonal T-cell response is drawn towards the tumour cells. T-DM1-resistant, HER-2/neupositive cell lines respond particularly well to such TDBs [59].

The most important update of the year concerning therapy for HER-2/neu-positive, metastatic breast cancer came from [60]. The CLEOPATRA study (authorisation trial of pertuzumab in combination with trastuzumab and docetaxel) revealed unprece-

\begin{tabular}{|c|c|c|c|}
\hline Agent & Phase & Regimen & Patients (Planned Enrolment, $\mathbf{n}$ ) \\
\hline \multirow[t]{3}{*}{ Palbociclib (PD0332991) } & phase III (PALOMA-2) (NCT01740427) & palbociclib + LET vs. LET + PBO & ER+, HER2- MBC (450) \\
\hline & phase III (PALOMA-3) (NCT01942135) & palbociclib + FUL vs. FUL + PBO & $\begin{array}{l}\text { ER+, HER2- MBC or LABC after progression } \\
\text { under anti-endocrine therapy (417) }\end{array}$ \\
\hline & $\begin{array}{l}\text { phase I/II (TRIO-18/PALOMA-1) } \\
\text { (NCT00721409) }\end{array}$ & PD0332991 + LET vs. LET & $\begin{array}{l}\text { Untreated ER+, HER2- MBC without previous } \\
\text { treatment for MBC (177) }\end{array}$ \\
\hline \multirow[t]{3}{*}{ LEE011 } & $\begin{array}{l}\text { phase III (MONALEESA-2) } \\
\text { (NCT01958021) }\end{array}$ & LEE011 + LET vs. LET + PBO & $\begin{array}{l}\text { ER+, HER2- MBC without previous treatment } \\
\text { for MBC ( } 500)\end{array}$ \\
\hline & phase I/II (NCT01857193) & LEE011 + EVE + EXE & $\begin{array}{l}\text { ER+, HER2 - MBC or LABC resistance towards LET } \\
\text { or ANA (185) }\end{array}$ \\
\hline & phase I/II (NCT01872260) & LEE011 + BYL719 + LET & $E R+M B C$ or $L A B C(130)$ \\
\hline Abemaciclib (LY2835219) & phase III (MONARCH-2) NCT02107703 & abemaciclib + FUL vs. FUL & $\begin{array}{l}\text { ER+, HER2- MBC (no previous anti-endocrine } \\
\text { therapy or progression under prior therapy with } \\
\text { Al or TAM) }(550)\end{array}$ \\
\hline
\end{tabular}

MBC: metastatic breast cancer; LET: letrozole; PBO: placebo; FUL: fulvestrant; ANA: anastrozole; EVE: everolimus; Al: aromatase inhibitor; TAM: tamoxifen; EXE: exemestane; LABC: local advances, inoperable breast cancer 


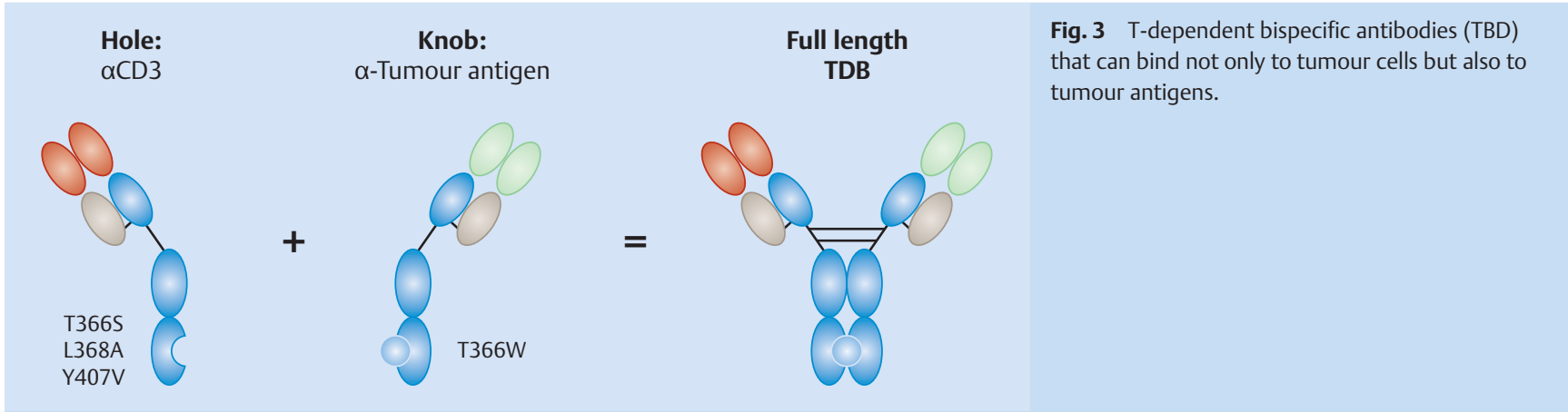

dented overall survival rates in the first-line therapy for advanced HER2-positive breast cancers. At a median follow-up of 50 months the statistically significant improvement in overall survival for the combination of pertuzumab/trastuzumab/docetaxel amounted to 56.5 months in comparison to that of 40.8 months $(H R=0.68, p=0.0002)$ for the sole administration of trastuzumab/docetaxel. This benefit in overall survival could be demonstrated in all the subgroups previously defined by the protocol and was valid in spite of crossovers of 48 patients in the placebo arm to the pertuzumab arm.

The results of the BOLERO- 1 study did not fulfil the expectations [61]. In the first-line therapy for HER2-positive breast cancers the combination of weekly paclitaxel, trastuzumab and everolimus (at a daily dose of $10 \mathrm{mg}$ ) could not improve the progression-free survival at an HR of 0.89 (95\% CI 0.73, 1.08). Here the median, relative dose intensity of everolimus amounted to merely $5 \mathrm{mg}$ because of dose reductions in the course of side effect management. Just how little is known about regulatory phenomena and their time-dependencies is shown by data for the combination or sequence of pertuzumab and T-DM1 in cell culture systems [62]. A "pre-treatment" of HER2-positive breast cancer cells with pertuzumab markedly reduced the efficacy of T-DM1 in comparison to the simultaneous exposure to both drugs. These data were not, as is frequently the case in preclinical systems, obtained with very high (not achievable in humans) doses but rather with the markedly lower doses than would be used clinically. These results will be extremely important for clinical studies in order to realise large effects with small means.

\section{Immune Biology and Immune Therapy \\ $\nabla$}

Our understanding of the immunological aspects of breast cancer is continuously improving. On the one hand the detection of peritumoural immunological cells can be considered as a prognostic [63] and even a predictive factor for responses to a neoadjuvant, platinum-containing chemotherapy for triple negative breast cancer [64]. The local detection of immunological reactions is, however, only successful for a small proportion of the patients and as yet prospective studies to reveal a therapeutic relevance are lacking.

In a large proportion of breast cancer diseases immunological reactions can be detected in lymphoid organs such as bone marrow [65], but these reactions appear to be suppressed in peripheral tissue. The recruitment of regulatory T-cells by the tumour itself seems to be a major mechanism for this immune escape. The activation of regulatory T-cells is mediated by an antigen of programmed cell death (PD-1) that can be expressed by tumour cells. The ligand is PD-L1 or PD-L2 which, in turn, is expressed by antigen-presenting cells such as dendritic cells. The detection of PD-1 in breast cancer cells is correlated with a poorer prognosis [66] since immune reactions are prevented by inhibitory interactions with antigen-presenting cells. The PD- 1 antibodies nivolumab and pembrolizumab are currently undergoing clinical trials, and have already been successfully tested against malignant melanoma [67]. CTLA-4 (cytotoxic T-lymphocyte associated protein 4 ) is a further antigen that mediates the immune escape of tumour cells and is expressed on T-helper cells. Blockade of CTLA- 4 by the antibody ipilimumab has led to clinical successes. However, autoimmune reactions (pancreatitis) were observed in some of the patients.

Apart from these immunomodulatory therapeutic options, active and passive vaccination strategies have been examined. Above all HER2 antigens are employed as active vaccinations in order to achieve primary or secondary prevention of the primary disease or a recurrence of an HER2-positive breast cancer [68]. Passive vaccinations by the administration of immunocompetent effector cells are a very elaborate but also very promising therapeutic option that is currently under investigation in some centres.

\section{Biomarkers \\ $\nabla$}

\section{Markers of gene expression}

The longest known and clinically most relevant biomarkers are markers at the level of gene expression measured on the amount of protein present. Examples include the oestrogen receptor or the progesterone receptor. Since the discovery of molecular subtypes, determinations of gene expression have developed further not only in regard to the number of particular markers but also with regard to the analytical methods. In the so-called multigene tests, for example, gene expression is determined at the mRNA level. In this way numerous genes can be determined simultaneously with a high quality. Analyses of gene expression at the mRNA level are, like immunohistological investigations, determined on paraffin-embedded sample of the tumour. As examples of such tests we can mention the Oncotype DX Assay, the EndoPredict Test and the Prosigna Test, which is based on the PAM-50 risk-of-recurrence (ROR) score [1,2]. A further test involving the determination of mRNA in fresh tumour tissue is called Mammaprint. In Germany use of the OncotypeDX test is widespread within the framework of the planB study and the ADAPT study concept. Just recently it was shown that by use of this test on patients of the planB study the patients' prognosis could indeed be well described [69]. In this case patients with a low or medium risk score had a 3-year disease-free survival (3Y-DFS) of 98\%, 
whereas patients with a higher risk score had a 3 Y-DFS of $92 \%$ [69].

\section{Genetic changes of the tumour}

Bit by bit we are beginning to understand the reasons for different gene expression profiles in tumours whereby genetic changes in the tumour DNA appear to play a key role. In the past few years mutations and gene copy changes have been investigated genome-wide for their influence in the molecular subtypes and the prognosis of breast cancer [70-75]. While the significance of mutations and gene copy changes with regard to tumour pathogenesis was mainly investigated in the past few years, more and more work is now being done to systematically identify those genes that play a role in the prognosis. Thus by including genome-wide information on the number of gene copies it has been possible to markedly improve predictions on prognosis [71]. But these classifications have not yet been adopted in clinical practice. Also first studies have shed light on the significance of individual mutations for the response to certain therapies. In an analysis of several neoadjuvant studies in which patients were treated with an anti-HER2 therapy, it was shown that the therapy was most effective with regard to complete pathological remission when the patient did not have a mutation in gene PI3K [72]. When such a mutation existed, the anti-HER2 therapy was on average less effective. Ca. $19 \%$ of the patients with a mutation achieved complete remission under anti-HER2 therapy whereas the complete remission rate for patients with a tumour but without the mutation was 33\% [72]. It will be exciting to see in future which gene will, with regard to its genetic alterations, find use as a prognostic and predictive parameter in clinical practice.

\section{The significance of genetic variants of the germ-line}

Not only somatic variants but also hereditary germ-line changes have been discussed in the context of the prognosis of breast cancers. The genetic disposition with which the patient is born can lead to a specific molecular subtype of breast cancer. The most prominent example is provided by patients with a BRCA1 mutation. If a woman with a BRCA1 mutation should develop breast cancer, the probability that the tumour is triple negative is greater than $50 \%[45,46,76]$. Also, other less obtrusive genetic variants that are associated with a specific molecular subtype have been described [77-83]. Some of them are, similar to BRCA1 and $B R C A 2$, relevant not only for breast cancer but also for ovarian cancer [84-86]. Thus, it is not surprising that genetic variants can also be associated with the prognosis after breast cancer disease [87-90]. At present some studies are in the active recruiting phase (OLYMPIA, BRIGHTNESS, EMBRACA, ABRAZO) in which the efficacy PARP inhibition will be examined in patients with BRCA1 or BRCA2 [48-50,91]. These studies place new challenges on the study landscape since the therapy can only be offered to a small proportion of the patients who will have to be clearly defined prior to the trial.

\section{Circulating tumour cells and circulating tumour nucleic acids}

Even if there is some hereditary genetic information that can help in therapy planning, most biomarkers are determined on the tumour itself. Against this background attempts to determine tumour characteristics from the blood are of particular interest. These analytical methods are designated as "liquid biopsies".

Just the presence of circulating tumour cells (CTC) in blood can be consistently associated with the prognosis of patients with meta- static breast cancer [92-95]. The presence of CTCs is also an independent prognostic factor in the non-metastatic situation [96]. The next logical step is the determination of the molecular properties of the circulating tumour cells $[97,98]$. To what extent this can help in therapy planning and prediction of the prognosis are questions to be answered by ongoing clinical studies [99-102].

The analysis of circulating nucleic acids may be less elaborate than CTC analysis. Tumour cells in the body release small amounts of, e.g., DNA into the blood circulation. This is designated as circulating DNA (ctDNA). Various analyses of ctDNA are possible. These range from the determination of known point mutations to the sequencing of entire gene regions or to the determination of gene copy changes in specific gene regions. Further genotyping methods are currently under development. Thus, genotyping of ctDNA should offer a relatively practicable method to investigate changes in the genome over the course of a tumour disease, e.g., the progression or as a control for therapy response. An example for such changes during therapy has been illustrated by an investigation of solid tumour material in the course of an antihormonal therapy [103]. It was shown that the molecular patterns of somatic mutations change specifically in response to therapy and during the progress of therapy. Just how this can be exploited for therapy planning and therapy monitoring is not yet clear. However, if such investigations should also be possible on blood, one could feasibly obtain an early indication on the efficacy of a therapy. The first small studies have provided promising results with regard to the agreement of mutations that were determined on tumour material and ctDNA from one and the same patient [104].

\section{eHealth in Individualised Health-Care \\ $\nabla$}

With the increasing communication and information demands of the breast cancer patient on the one hand and the increasing networking on the part of health-care suppliers on the other hand [105] the potentials for eHealth solutions in health-care research are obvious. Here, eHealth is defined as the use of electronic media for information and communication processes in medicine [106]. Distinctions are thereby made between use for the patient/health-care supplier interaction (e.g., recording health status, monitoring side effects and quality of life), self-management for the patients (e.g., interventions to prevent side effects) and health-care supplier/health-care supplier interactions by means of electronic health records (EHR).

For many indications there are already successful examples of use as support for the doctor/patient interaction: the application of an online intervention could, e.g., achieve a significant reduction of depression [107]. Also the employment of weekly SMS reminders has resulted in a demonstrable benefit for patients with chronic pain [108]. The use of SMS was proved to be helpful in the management of patients with chemotherapy-induced nausea [109].

In the framework of the platform www.brustkrebs-studien.de from Senopedia, already today patients can obtain information about potentially relevant clinical studies and pose individual questions about their suitability.

In the forefront of optimisation of quality of life and individual therapy management we find, among others, the early identification of specific side effects such as, for example, stomatitis under everolimus therapy. Early identification together with a consecutive supporting therapy could perhaps prevent progression to a 
higher-degree adverse event (AE). The patient-centred documentation of "patient reported outcomes" (PRO) offers an especially high potential. By means of eHealth algorithms high-risk patients can potentially be recognised and individual treatments initiated in good time. In a randomised, German study [110] a tabletbased screening of 206 patients was evaluated, and the acceptance was superior to that of a conventional approach. Beside the lower documentation requirements in the centre, high-risk patients could be identified without delay and referred to further treatment. In a recent publication, web-based $\mathrm{AE}$ reporting showed a high long-term acceptance among 381 oncological patients [111] with a monthly adherence of $75 \%$ over a follow-up period of 34 weeks. As a further support weekly remainders were sent by e-mail.

A pilot study has demonstrated a high user satisfaction with a patient-centred portal for the documentation of side effects under chemotherapy with general recommendations for action among 55 patients [112]. The integration of the patient and other target groups in this health-care system represents a major challenge for health-care research as do the requirements of data protection, the medical products laws and the pharmaceutical advertising laws.

For an outlook we need to evaluate the successful pilot studies in multicentre settings and in the context of eHealth applications to define an adequate balance between private sphere and user friendliness for the participants. The objective is an improvement in quality of life for the patients. Modern, internet-based interaction portals can react flexibly to the needs of the patient and at the same time help to conserve resources. In the framework of the PRAEGNANT study [50] the various PRO modules in the fields quality of life, therapy adherence (compliance), sport, nutrition, and adverse events were tested and validated.

\section{Conclusion}

On the whole it is apparent that therapy for breast cancer is developing more and more in the direction of individualised precision medicine in dependence on the characteristic of the tumour and the patient. New therapies and molecular, diagnostic tests are showing significant progress and give rise to hope for further therapeutic successes in the next few years. The understanding of new molecular diagnostics and therapies must be promoted and integration of the results into clinical practice should be the focus of scientific efforts in the years to come.

\section{Conflicts of Interest \\ $\nabla$}

PAF has received fees for lectures from Amgen, Novartis, Genomic Health, Pfizer, Roche and Teva. PAF has carried out research for Amgen and Novartis. MPL has received fees for lectures and consultations from Novartis, Roche, Medac, Eisai, GSK, AstraZeneca and Celgene. MPL has carried out research for Novartis. NM has received fees from AstraZeneca, Novartis, Teva, Amgen, Eisai, Pfizer, Roche. SK has received fees for lectures from Amgen, Novartis, Genomic Health, Roche, Celgene and Teva. SK has carried out research for Roche. FS has received fees for lectures from Amgen, Novartis, Roche, Celgene and AstraZeneca. WJ has received fees for lectures from Amgen, Novartis, Genomic Health, Pfizer, Roche, AstraZeneca, Sanofi, Chugai, Verridex, GSK and Teva. HCK has received fees for lectures and consultations from Amgen, No- vartis, Teva, Pfizer, Carl Zeiss Meditec, GSK and Roche. All other authors declare that they have no conflicts of interest. The coordinate effort of this article was supported by an unrestricted grant from Novartis Pharma GmbH, Germany. No medical writing services were used.

\section{Affiliations}

${ }^{1}$ Department of Gynecology and Obstetrics, University Hospital Aachen, Aachen

2 Frauenklinik, Universitätsklinikum Heidelberg, Heidelberg

3 Department of Gynecology and Obstetrics, University Hospital Erlangen,

Friedrich-Alexander University Erlangen-Nuremberg, Comprehensive Cancer Center Erlangen-EMN, Erlangen

${ }^{4}$ Department of Gynecology and Obstetrics, University Hospital Düsseldorf,

Heinrich Heine Universität Düsseldorf, Düsseldorf

${ }^{5}$ Frauenklinik, Klinikum der Universität Ulm, Ulm

${ }^{6}$ Brustzentrum, Kliniken Essen Mitte, Evang. Huyssens-Stiftung/Knappschaft $\mathrm{GmbH}$, Essen

${ }^{7}$ Klinik für Gynäkologie und Geburtshilfe, Marienhospital Bottrop, Bottrop

${ }^{8}$ Medizinische Klinik und Poliklinik II, Campus Charité Mitte, Berlin

\section{References}

1 Schmidt M, Fasching PA, Beckmann MW et al. Biomarkers in breast cancer - an update. Geburtsh Frauenheilk 2012; 72: 819-832

2 Sinn P, Aulmann S, Wirtz $R$ et al. Multigene assays for classification, prognosis, and prediction in breast cancer: a critical review on the background and clinical utility. Geburtsh Frauenheilk 2013; 73: 932940

3 Eisemann N, Waldmann A, Katalinic A. Epidemiology of breast cancer current figures and trends. Geburtsh Frauenheilk 2013; 73: 130-135

4 Huober J, von Minckwitz G, Denkert C et al. Effect of neoadjuvant anthracycline-taxane-based chemotherapy in different biological breast cancer phenotypes: overall results from the GeparTrio study. Breast Cancer Res Treat 2010; 124: 133-140

5 Lux MP, Maass N, Schütz F et al. Breast cancer 2013 - interpretation of new and known data. Geburtsh Frauenheilk 2013; 73: 584-598

6 von Minckwitz G, Untch M, Blohmer JU et al. Definition and impact of pathologic complete response on prognosis after neoadjuvant chemotherapy in various intrinsic breast cancer subtypes. J Clin Oncol 2012; 30: $1796-1804$

7 Cortazar P, Zhang L, Untch M et al. Pathological complete response and long-term clinical benefit in breast cancer: the CTNeoBC pooled analysis. Lancet 2014; 384: 164-172

8 Fasching PA, Heusinger K, Haeberle L et al. Ki67, chemotherapy response, and prognosis in breast cancer patients receiving neoadjuvant treatment. BMC Cancer 2011; 11: 486

9 Paluch-Shimon S, Friedman E, Berger $R$ et al. Does pathologic complete response predict for outcome in BRCA mutation carriers with triplenegative breast cancer? J Clin Oncol 2014; 32 (Suppl.): Abstr. 1023

10 Kummel S, Holtschmidt J, Loibl S. Surgical treatment of primary breast cancer in the neoadjuvant setting. Br J Surg 2014; 101: 912-924

11 Petrelli F, Coinu A, Borgonovo $K$ et al. The value of platinum agents as neoadjuvant chemotherapy in triple-negative breast cancers: a systematic review and meta-analysis. Breast Cancer Res Treat 2014; 144: 223-232

12 von Minckwitz G, Schneeweiss A, Loibl S et al. Neoadjuvant carboplatin in patients with triple-negative and HER2-positive early breast cancer (GeparSixto; GBG 66): a randomised phase 2 trial. Lancet Oncol 2014; 15: 747-756

13 von Minckwitz G, Hahnen E, Fasching PA et al. Pathological complete response ( $\mathrm{pCR}$ ) rates after carboplatin-containing neoadjuvant chemotherapy in patients with germline BRCA (gBRCA) mutation and triplenegative breast cancer (TNBC): Results from GeparSixto. J Clin Oncol 2014; 32 (Suppl.): Abstr. 1023

14 Untch M, Fasching PA, Konecny GE et al. Pathologic complete response after neoadjuvant chemotherapy plus trastuzumab predicts favorable survival in human epidermal growth factor receptor 2-overexpressing breast cancer: results from the TECHNO trial of the AGO and GBG study groups. J Clin Oncol 2011; 29: 3351-3357

15 Gradishar WJ, Krasnojon D, Cheporov S et al. Significantly longer progression-free survival with nab-paclitaxel compared with docetaxel as first-line therapy for metastatic breast cancer. J Clin Oncol 2009; 27: $3611-3619$ 
16 Earl HM, Vallier AL, Hiller L et al. Effects of the addition of gemcitabine, and paclitaxel-first sequencing, in neoadjuvant sequential epirubicin, cyclophosphamide, and paclitaxel for women with high-risk early breast cancer (Neo-tAnGo): an open-label, $2 \times 2$ factorial randomised phase 3 trial. Lancet Oncol 2014; 15: 201-212

17 Kommission Mamma der Arbeitsgemeinschaft für Gynäkologische Onkologie (AGO-Mamma). Diagnosis and treatment of patients with primary and metastatic breast cancer. Online: http://www.ago-online.de/de/ infothek-fuer-aerzte/leitlinienempfehlungen/mamma/maerz-2013/ 2014; last update: 28.03.2014; Stand: 05.01.2015

18 Giuliano AE, Hunt KK, Ballman KV et al. Axillary dissection vs. no axillary dissection in women with invasive breast cancer and sentinel node metastasis: a randomized clinical trial. JAMA 2011; 305: 569575

19 Kuehn T, Bauerfeind I, Fehm T et al. Sentinel-lymph-node biopsy in patients with breast cancer before and after neoadjuvant chemotherapy (SENTINA): a prospective, multicentre cohort study. Lancet Oncol 2013; 14: 609-618

20 Boughey JC, Suman VJ, Mittendorf EA et al. Sentinel lymph node surgery after neoadjuvant chemotherapy in patients with node-positive breast cancer: the ACOSOG Z1071 (Alliance) clinical trial. JAMA 2013; 310: 1455-1461

21 Fitzal F, Filipits $M$, Fesl $C$ et al. Predicting local recurrence using PAM50 in postmenopausal endocrine responsive breast cancer patients. J Clin Oncol 2014; 32 (Suppl.): Abstract 1008

22 Nielsen TO, Parker JS, Leung S et al. A comparison of PAM50 intrinsic subtyping with immunohistochemistry and clinical prognostic factors in tamoxifen-treated estrogen receptor-positive breast cancer. Clin Cancer Res 2010; 16: 5222-5232

23 Prat A, Parker JS, Fan C et al. PAM50 assay and the three-gene model for identifying the major and clinically relevant molecular subtypes of breast cancer. Breast Cancer Res Treat 2012; 135: 301-306

24 Martín M, Prat A, Rodríguez-Lescure A et al. PAM50 proliferation score as a predictor of weekly paclitaxel benefit in breast cancer. Breast Cancer Res Treat 2013; 138: 457-466

25 Filipits $M$, Rudas $M$, Jakesz R et al.; EP Investigators. A new molecular predictor of distant recurrence in ER-positive, HER2-negative breast cancer adds independent information to conventional clinical risk factors. Clin Cancer Res 2011; 17: 6012-6020

26 Denkert $C$, Kronenwett $R$, Schlake $W$ et al. Decentral gene expression analysis for ER+/Her2- breast cancer: results of a proficiency testing program for the EndoPredict assay. Virchows Arch 2012; 460: 251-259

27 Dubsky P, Filipits M, Jakesz R et al. EndoPredict improves the prognostic classification derived from common clinical guidelines in ER-positive, HER2-negative early breast cancer. Ann Oncol 2013; 24: 640-647

28 Fitzal F, Filipits MF, Rudas $M$ et al. Tailoring local therapy in post-menopausal endocrine responsive HER2neu negative breast cancer patients based on their genetic risk profile using Endopredict. Eur J Cancer 2014; 50: S97-S97

29 Goss PE, Ingle JN, Martino $S$ et al. Impact of premenopausal status at breast cancer diagnosis in women entered on the placebo-controlled NCIC CTG MA17 trial of extended adjuvant letrozole. Ann Oncol 2013; 24: $355-361$

30 Francis PA, Regan MM, Fleming GF et al.; International Breast Cancer Study Group. Adjuvant ovarian suppression in premenopausal breast cancer. N Engl J Med 2015; 372: 436-446

31 Pagani O, Regan MM, Walley BA et al. Adjuvant exemestane with ovarian suppression in premenopausal breast cancer. N Engl J Med 2014; 371: $107-118$

32 Regan MM, Pagani O, Fleming GF et al. Adjuvant treatment of premenopausal women with endocrine-responsive early breast cancer: design of the TEXT and SOFT trials. Breast 2013; 22: 1094-1100

33 Francis PA, Regan MM, Fleming GF et al. Randomized comparison of adjuvant tamoxifen (T) plus ovarian function suppression (OFS) versus tamoxifen in premenopausal women with hormone receptor-positive $(\mathrm{HR}+$ ) early breast cancer (BC): analysis of the SOFT trial. San Antonio Breast Cancer Symposium 2014; S3-08

34 von Minckwitz G, Reimer T, Potenberg J et al. The phase III ICE study: adjuvant ibandronate with or without capecitabine in elderly patients with moderate or high risk early breast cancer. San Antonio Breast Cancer Symposium 2014; S3-04
35 Samuel JA, Wilson JW, Bandos $\mathrm{H}$ et al. NSABP B-36: a randomized phase III trial comparing six cycles of 5-fluorouracil (5-FU), epirubicin, and cyclophosphamide (FEC) to four cycles of adriamycin and cyclophosphamide (AC) in patients (pts) with node-negative breast cancer. San Antonio Breast Cancer Symposium 2014; S3-02

36 Sparano JA, Zhao F, Martino S et al. Ten year update of E1199: phase III study of doxorubicin-cyclophosphamide followed by paclitaxel or docetaxel given every 3 weeks or weekly in patients with axillary nodepositive or high-risk node-negative breast cancer. San Antonio Breast Cancer Symposium 2014; S3-03

37 Twelves C, Nasim MY, Anthoney A et al. Efficacy and safety of eribulin in combination with capecitabine in patients with metastatic breast cancer: an open-label, phase II dose-confirmation study. San Antonio Breast Cancer Symposium 2014; P3-13-04

38 Blum JL, Dieras V, Lo Russo PM et al. Multicenter, phase II study of capecitabine in taxane-pretreated metastatic breast carcinoma patients. Cancer 2001; 92: 1759-1768

39 Vahdat LT, Pruitt B, Fabian CJ et al. Phase II study of eribulin mesylate, a halichondrin $B$ analog, in patients with metastatic breast cancer previously treated with an anthracycline and a taxane. J Clin Oncol 2009; 27: 2954-2961

40 Untch M, von Minckwitz G, Konecny GE et al. PREPARE trial: a randomized phase III trial comparing preoperative, dose-dense, dose-intensified chemotherapy with epirubicin, paclitaxel, and CMF versus a standard-dosed epirubicin-cyclophosphamide followed by paclitaxel with or without darbepoetin alfa in primary breast cancer-outcome on prognosis. Ann Oncol 2011; 22: 1999-2006

41 Untch M, Fasching PA, Konecny GE et al. PREPARE trial: a randomized phase III trial comparing preoperative, dose-dense, dose-intensified chemotherapy with epirubicin, paclitaxel and CMF versus a standarddosed epirubicin/cyclophosphamide followed by paclitaxel \pm darbepoetin alfa in primary breast cancer-results at the time of surgery. Ann Oncol 2011; 22: 1988-1998

42 Bohlius J, Schmidlin K, Brillant C et al. Erythropoietin or darbepoetin for patients with cancer-meta-analysis based on individual patient data. Cochrane Database Syst Rev 2009; 3: CD007303

43 Aapro M, Moebus V, Nitz $U$ et al. Safety and efficacy outcomes with erythropoiesis-stimulating agents in patients with breast cancer: a meta-analysis. Ann Oncol 2014; DOI: 10.1093/annonc/mdu579

44 Leyland-Jones B, Bondarenko I, Nemsadze G et al. A randomized, openlabel, multicenter, phase 3 study of epoetin alfa (EPO) plus standard supportive care versus standard supportive care in anemic patients with metastatic breast cancer $(\mathrm{MBC})$ receiving standard chemotherapy. San Antonio Breast Cancer Symposium 2014; S5-07

45 Couch FJ, Hart SN, Sharma P et al. Inherited mutations in 17 breast cancer susceptibility genes among a large triple-negative breast cancer cohort unselected for family history of breast cancer. J Clin Oncol 2014; DOI: 10.1200/JCO.2014.57.1414

46 Fasching PA, Ekici AB, Wachter DL et al. Breast cancer risk - from genetics to molecular understanding of pathogenesis. Geburtsh Frauenheilk 2013; 73: 1228-1235

47 Tutt A, Ellis P, Kilburn L et al. The TNT trial: a randomized phase III trial of carboplatin(C) compared with docetaxel (D) for patients with metastatic or recurrent locally advanced triple negative or BRCA $1 / 2$ breast cancer (CRUK/07/012). San Antonio Breast Cancer Symposium 2014; S3-01

48 Litton JK, Blum JL, Eiermann Wet al. A phase 3, open-label, randomized, parallel, 2-arm multi-center study of the oral PARP inhibitor BMN 673 versus physician's choice in germline BRCA mutation subjects with locally advanced and/or metastatic breast cancer (EMBRACA study). San Antonio Breast Cancer Symposium 2014; OT1-1-12

49 Turner NC, Balmana J, Domcheck SM et al. A phase 2, 2-stage, 2-cohort study of the oral PARP inhibitor BMN 673 in patients withgermline BRCA mutation and locally advanced and/or metastatic breast cancer (ABRAZO study). San Antonio Breast Cancer Symposium 2014; OT1$1-14$

50 Fasching PA, Brucker SY, Fehm TN et al. Biomarkers in patients with metastatic breast cancer and the PRAEGNANT study network. Geburtsh Frauenheilk 2015; 75: 41-50

51 Fruman DA, Rommel C. PI3K and cancer: lessons, challenges and opportunities. Nat Rev Drug Discov 2014; 13: 140-156

$52 \mathrm{Fu}$ X, Osborne CK, Schiff R. Biology and therapeutic potential of PI3K signaling in ER+/HER2-negative breast cancer. Breast 2013; 22 (Suppl. 2): S12-S18 
53 Choi YJ, Anders L. Signaling through cyclin D-dependent kinases. Oncogene 2014; 33: 1890-1903

54 Finn RS, Dering J, Conklin D et al. PD 0332991, a selective cyclin D kinase 4/6 inhibitor, preferentially inhibits proliferation of luminal estrogen receptor-positive human breast cancer cell lines in vitro. Breast Cancer Res 2009; 11: R77

55 Finn RS, Crown JP, Lang I et al. The cyclin-dependent kinase 4/6 inhibitor palbociclib in combination with letrozole versus letrozole alone as first-line treatment of oestrogen receptor-positive, HER2-negative, advanced breast cancer (PALOMA-1/TRIO-18): a randomised phase 2 study. Lancet Oncol 2015; 16: 25-35

56 Rocca A, Farolfi A, Bravaccini S et al. Palbociclib (PD 0332991): targeting the cell cycle machinery in breast cancer. Expert Opin Pharmacother 2014; 15: 407-420

57 Patnaik A, Rosen LS, Tolaney SM et al. LY2835219, a novel cell cycle inhibitor selective for CDK4/6, in combination with fulvestrant for patients with hormone receptor positive (HR+) metastatic breast cancer. J Clin Oncol 2014; 32 (Suppl.): Abstract 534

58 Munster PN, Hamilton EP, Franklin C et al. Phase lb study of LEE011 and BYL719 in combination with letrozole in estrogen receptor-positive, HER2-negative breast cancer (ER+, HER2- BC). J Clin Oncol 2014; 32 (Suppl.): Abstract 533

59 Junttila TT, Li J, Johnston J et al. HER2 T cell dependent bispecific antibody (HER2-TDB) for treatment of HER2 positive breast cancer. San Antonio Breast Cancer Symposium 2014; S1-07

60 Swain SM, Kim S, Cortes J et al. Final overall survival (OS) analysis from the CLEOPATRA study of first-line (1 L) pertuzumab (Ptz), trastuzumab $(\mathrm{t})$, and docetacel (D) in patients (pts) with HER2-positive metastatic breast cancer (MBC). European Society of Medical Oncology Meeting (ESMO) 2014

61 Hurvitz SA, Andre F, Jiang $Z$ et al. Phase 3, randomized, double-blind, placebo-controlled multicenter trial of daily everolimus plus weekly trastuzumab and paclitaxel as first-line therapy in women with HER2 + advanced breast cancer: BOLERO-1. San Antonio Breast Cancer Symposium 2014; S6-01

62 Korkola JE, Liu M, Liby T et al. Detrimental effects of sequential compared to concurrent treatment of pertuzumab plus T-DM1 in HER2+ breast cancer cell lines. San Antonio Breast Cancer Symposium 2014; S6-07

63 Ali HR, Provenzano E, Dawson SJ et al. Association between CD8+ T-cell infiltration and breast cancer survival in 12,439 patients. Ann Oncol 2014; 25: 1536-1543

64 Denkert C, von Minckwitz G, Brase JC et al. Tumor-infiltrating lymphocytes and response to neoadjuvant chemotherapy with or without carboplatin in human epidermal growth factor receptor 2-positive and triple-negative primary breast cancers. J Clin Oncol 2014; DOI: 10.1200/JCO.2014.58.1967

65 Sommerfeldt N, Schütz F, Sohn C et al. The shaping of a polyvalent and highly individual T-cell repertoire in the bone marrow of breast cancer patients. Cancer Res 2006; 66: 8258-8265

66 Muenst S, Schaerli AR, Gao F et al. Expression of programmed death ligand 1 (PD-L1) is associated with poor prognosis in human breast cancer. Breast Cancer Res Treat 2014; 146: 15-24

67 Robert C, Long GV, Brady B et al. Nivolumab in previously untreated melanoma without BRAF mutation. N Engl J Med 2015; 372: 320-330

68 Milani A, Sangiolo D, Aglietta $M$ et al. Recent advances in the development of breast cancer vaccines. Breast Cancer (Dove Med Press) 2014; 6: $159-168$

69 Nitz U, Gluz O, Kates RE et al. Prognostic impact of discordance between different risk assessment tools in early breast cancer (recurrence score, central grade, Ki67): early outcome analysis from the prospective phase III WSG-PlanB trial. San Antonio Breast Cancer Symposium 2014; P4-11-01

70 Cancer Genome Atlas N. Comprehensive molecular portraits of human breast tumours. Nature 2012; 490: 61-70

71 Curtis C, Shah SP, Chin SF et al. The genomic and transcriptomic architecture of 2,000 breast tumours reveals novel subgroups. Nature 2012; 486: 346-352

72 Loibl S, von Minckwitz G, Schneeweiss A et al. PIK3CA mutations are associated with lower rates of pathologic complete response to anti-human epidermal growth factor receptor 2 (HER2) therapy in primary HER2-overexpressing breast cancer. J Clin Oncol 2014; 32: 3212-3220
73 Baselga J, Piccart M, Gnant $M$ et al. Minimal molecular alteration in PI3KCA, FGFR1 and CCND1 is associated with increased benefit from everolimus in hormone receptor-positive, HER2-advanced breast cancer: Insights from the BOLERO-2 trial. Eur J Cancer 2013; 49: S404S405

74 Ellis MJ, Ding L, Shen D et al. Whole-genome analysis informs breast cancer response to aromatase inhibition. Nature 2012; 486: 353-360

75 Shah SP, Roth A, Goya R et al. The clonal and mutational evolution spectrum of primary triple-negative breast cancers. Nature 2012; 486: 395-399

76 Lakhani SR, Reis-Filho JS, Fulford L et al. Prediction of BRCA1 status in patients with breast cancer using estrogen receptor and basal phenotype. Clin Cancer Res 2005; 11: 5175-5180

77 Stevens KN, Vachon CM, Lee AM et al. Common breast cancer susceptibility loci are associated with triple-negative breast cancer. Cancer Res 2011; 71: 6240-6249

78 Stevens KN, Fredericksen Z, Vachon CM et al. 19p13.1 is a triple negative-specific breast cancer susceptibility locus. Cancer Res 2012; 72: 1795-1803

79 Purrington KS, Slager S, Eccles D et al. Genome-wide association study identifies 25 known breast cancer susceptibility loci as risk factors for triple negative breast cancer. Carcinogenesis 2014; 35: 1012-1019

80 Garcia-Closas M, Couch FJ, Lindstrom S et al. Genome-wide association studies identify four ER negative-specific breast cancer risk loci. Nat Genet 2013; 45: 392-398

81 Broeks A, Schmidt MK, Sherman ME et al. Low penetrance breast cancer susceptibility loci are associated with specific breast tumor subtypes: findings from the Breast Cancer Association Consortium. Hum Mol Genet 2011; 20: 3289-3303

82 Figueroa JD, Garcia-Closas M, Humphreys $M$ et al. Associations of common variants at $1 \mathrm{p} 11.2$ and 14q24.1 (RAD51L1) with breast cancer risk and heterogeneity by tumor subtype: findings from the Breast Cancer Association Consortium. Hum Mol Genet 2011; 20: 4693-4706

83 French JD, Ghoussaini M, Edwards SL et al. Functional variants at the $11 \mathrm{q} 13$ risk locus for breast cancer regulate cyclin D1 expression through long-range enhancers. Am J Hum Genet 2013; 92: 489-503

84 Antoniou AC, Wang X, Fredericksen ZS et al. A locus on 19p13 modifies risk of breast cancer in BRCA1 mutation carriers and is associated with hormone receptor-negative breast cancer in the general population. Nat Genet 2010; 42: 885-892

85 Bolton KL, Tyrer J, Song $H$ et al. Common variants at 19p13 are associated with susceptibility to ovarian cancer. Nat Genet 2010; 42: 880884

86 Fasching PA, Gayther S, Pearce L et al.; OCAC (Ovarian Cancer Association Consortium). Role of genetic polymorphisms and ovarian cancer susceptibility. Mol Oncol 2009; 3: 171-181

87 Azzato EM, Tyrer J, Fasching PA et al. Association between a germline OCA2 polymorphism at chromosome 15q13.1 and estrogen receptornegative breast cancer survival. J Natl Cancer Inst 2010; 102: 650-662

88 Fasching PA, Loehberg CR, Strissel PL et al. Single nucleotide polymorphisms of the aromatase gene (CYP19A1), HER2/neu status, and prognosis in breast cancer patients. Breast Cancer Res Treat 2008; 112: 89-98

89 Fasching PA, Pharoah PD, Cox A et al. The role of genetic breast cancer susceptibility variants as prognostic factors. Hum Mol Genet 2012; 21: 3926-3939

90 Weischer M, Nordestgaard BG, Pharoah Pet al. CHEK2*1100delC heterozygosity in women with breast cancer associated with early death, breast cancer-specific death, and increased risk of a second breast cancer. J Clin Oncol 2012; 30: 4308-4316

91 Robson M, Tutt A, Balmaña J et al. OlympiA, Neo-Olympia and OlympiAD: Randomized phase III trials of olaparib in patients (pts) with breast cancer (BC) and a germline BRCA1/2 mutation (gBRCAm). San Antonio Breast Cancer Symposium 2014; OT1-1-04

92 Bidard FC, Peeters DJ, Fehm T et al. Clinical validity of circulating tumour cells in patients with metastatic breast cancer: a pooled analysis of individual patient data. Lancet Oncol 2014; 15: 406-414

93 Cristofanilli M, Budd GT, Ellis MJ et al. Circulating tumor cells, disease progression, and survival in metastatic breast cancer. $\mathrm{N}$ Engl J Med 2004; 351: 781-791

94 Müller V, Riethdorf S, Rack B et al.; DETECT study group. Prognostic impact of circulating tumor cells assessed with the CellSearch System ${ }^{\mathrm{TM}}$ and AdnaTest Breast ${ }^{\mathrm{TM}}$ in metastatic breast cancer patients: the DETECT study. Breast Cancer Res 2012; 14: R118 
95 Wallwiener M, Hartkopf AD, Baccelli I et al. The prognostic impact of circulating tumor cells in subtypes of metastatic breast cancer. Breast Cancer Res Treat 2013; 137: 503-510

96 Rack B, Schindlbeck C, JückstockJ et al. Circulating tumor cells predict survival in early average-to-high risk breast cancer patients. J Natl Cancer Inst 2014; DOI: 10.1093/jnci/dju066

97 Fehm T, Becker S, Duerr-Stoerzer S et al. Determination of HER2 status using both serum HER2 levels and circulating tumor cells in patients with recurrent breast cancer whose primary tumor was HER2 negative or of unknown HER2 status. Breast Cancer Res 2007; 9: R74

98 Fehm T, Müller V, Aktas B et al. HER2 status of circulating tumor cells in patients with metastatic breast cancer: a prospective, multicenter trial. Breast Cancer Res Treat 2010; 124: 403-412

99 Albrecht S, Schochter F, Melcher C et al. DETECT III - a multicenter, randomized, phase III trial to assess efficacy of lapatinib in patients with HER2-negative metastatic breast cancer and HER2-positive circulating tumor cells (CTCs). Oncol Res Treat 2014; 37: 29-29

100 Hagenbeck C, Melcher CA, Janni JW et al. DETECT III: a multicenter, randomized, phase III study to compare standard therapy alone versus standard therapy plus lapatinib in patients (pts) with initially HER2negative metastatic breast cancer but with HER2-positive circulating tumor cells (CTC). J Clin Oncol 2012; 30: Abstract TPS1146

101 Melcher C, Schochter F, Albrecht S et al. DETECT IV - a multicenter, single arm, phase II study evaluating the efficacy of Everolimus in combination with endocrine therapy in patients with HER2-negative, hormone-receptor positive metastatic breast cancer and exclusively HER2-negative circulating tumor cells (CTCs). Oncol Res Treat 2014; 37: $29-29$

102 Melcher CA, Janni W, Rack B et al. DETECT III - a multicenter, randomized, phase III study to compare standard therapy alone versus standard therapy plus lapatinib in patients with initially HER2-negative metastatic breast cancer and HER2-positive circulating tumor cells. Eur J Cancer 2012; 48: S95-S96

103 Dixon JM, Turnbull AK, Fan C et al. In-depth genomic analysis of ER+ breast cancers during development of endocrine resistance. San Antonio Breast Cancer Symposium 2014; S1-05

104 Rothé F, Laes JF, Lambrechts D et al. Plasma circulating tumor DNA as an alternative to metastatic biopsies for mutational analysis in breast cancer. Ann Oncol 2014; 25: 1959-1965

105 Smith A. Cell Internet use 2012. Pew Internet and American Life Project. Online: http://www.pewinternet.org/ /media//Files/Reports/ 2012/PIP_Cell_Phone_Internet_Access.pdf 2012; Stand: 26.06.2012

106 Eysenbach G. What is e-health? J Med Internet Res 2001; 3: E20

107 Clarke G, Eubanks D, Reid E et al. Overcoming Depression on the Internet (ODIN) (2): a randomized trial of a self-help depression skills program with reminders. J Med Internet Res 2005; 7: e16

108 Axén I, Bodin L, Bergström $G$ et al. The use of weekly text messaging over 6 months was a feasible method for monitoring the clinical course of low back pain in patients seeking chiropractic care. J Clin Epidemiol 2012; 65: 454-461
109 Yap KY, Low HX, Koh KS et al. Feasibility and acceptance of a pharmacist-run tele-oncology service for chemotherapy-induced nausea and vomiting in ambulatory cancer patients. Telemed J E Health 2013; 19: 387-395

110 Schäffeler N, Pfeiffer K, Grischke EM et al. [Acceptance and reliability of an electronic psychooncological screening of patients with breast cancer: a randomized controlled study]. Psychother Psychosom Med Psychol 2013; 63: 374-380

111 Judson TJ, Bennett AV, Rogak LJ et al. Feasibility of long-term patient self-reporting of toxicities from home via the Internet during routine chemotherapy. J Clin Oncol 2013; 31: 2580-2585

112 Due J, Christensen HG, Vestlev PM et al. Treatment adverse effect registration. A PC based electronic patient - hospital communication portal that allows registration of adverse effects of chemotherapy and returns advice and recommandations for action. San Antonio Breast Cancer Symposium 2014; P2-10-02

113 Baselga J, Campone M, Piccart M et al. Everolimus in postmenopausal hormone-receptor-positive advanced breast cancer. N Engl J Med 2012; 366: 520-529

114 Bachelot T, Bourgier C, Cropet Cet al. Randomized phase II trial of everolimus in combination with tamoxifen in patients with hormone receptor-positive, human epidermal growth factor receptor 2-negative metastatic breast cancer with prior exposure to aromatase inhibitors: a GINECO study. J Clin Oncol 2012; 30: 2718-2724

115 André F, O'Regan R, Ozguroglu $M$ et al. Everolimus for women with trastuzumab-resistant, HER2-positive, advanced breast cancer (BOLERO-3): a randomised, double-blind, placebo-controlled phase 3 trial. Lancet Oncol 2014; 15: 580-591

116 Rugo HS, Tredan 0 , Ro J et al. Results from the phase 2 trial of ridaforolimus, dalotuzumab, and exemestane compared to ridaforolimus and exemestane in advanced breast cancer. San Antonio Breast Cancer Symposium 2014; PD5-1

117 Mayer IA, Abramson VG, Isakoff SJ et al. Stand up to cancer phase Ib study of pan-phosphoinositide-3-kinase inhibitor buparlisib with letrozole in estrogen receptor-positive/human epidermal growth factor receptor 2-negative metastatic breast cancer. J Clin Oncol 2014; 32: $1202-1209$

118 Ma CX, Luo J, Naughton M et al. A phase I study of BKM120 and fulvestrant in postmenopausal women with estrogen receptor positive metastatic breast cancer. San Antonio Breast Cancer Symposium 2014; PD5-6

119 Krop I, Johnston S, Mayer IA et al. The FERGI phase II study of the PI3K inhibitor pictilisib (GDC-0941) plus fulvestrant vs. fulvestrant plus placebo in patients with ER+, aromatase inhibitor (AI)- resistant advanced or metastatic breast cancer. San Antonio Breast Cancer Symposium 2014; S2-02

120 Janku F, Juric D, Cortes $J$ et al. Phase I study of the PI3K $\alpha$ inhibitor BYL719 plus fulvestrant in patients with PIK3CA-altered and wild type ER+/HER2- locally advanced or metastatic breast cancer. San Antonio Breast Cancer Symposium 2014; PD5-5

121 Shah PD, Moynahan ME, Modi S et al. Phase I trial: PI3Ko inhibitor BYL719 plus aromatase inhibitor (AI) for patients with hormone receptor-positive (HR+) metastatic breast cancer (MBC). San Antonio Breast Cancer Symposium 2014; PD5-3 